\title{
In situ groundwater and sediment bioremediation: barriers and perspectives at European contaminated sites
}

\section{Mauro Majone ${ }^{1}$, Roberta Verdini ${ }^{1}$, Federico Aulenta ${ }^{2}$, Simona Rossetti ${ }^{2}$, Valter Tandoi ${ }^{2}$, Nicolas Kalogerakis ${ }^{3}$, Spiros Agathos ${ }^{4}$, Sebastià Puig ${ }^{5}$, Giulio Zanaroli ${ }^{6}$ and Fabio Fava ${ }^{6}$}

\footnotetext{
${ }^{1}$ Department of Chemistry, Sapienza University of Rome, P. le Aldo Moro 5, 00185 Rome, Italy

${ }^{2}$ Water Research Institute (IRSA-CNR), National Research Council, Via Salaria Km 29.300, 00015 Monterotondo (RM), Italy

${ }^{3}$ Department of Environmental Engineering, Technical University of Crete, Polytechneioupolis, GR-73100 Chania, Greece

${ }^{4}$ Earth and Life Institute (ELI), Bioengineering Unit (GEBI), Universite Catholique de Louvain, Louvain-la-Neuve 1348, Belgium

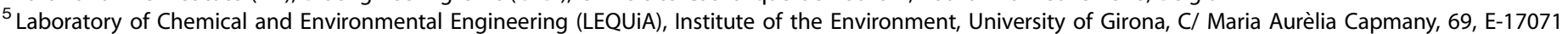
Girona, Spain

${ }^{6}$ Department of Civil, Chemical, Environmental and Materials Engineering (DICAM), University of Bologna, via Terracini 28,40131 Bologna, Italy
}

This paper contains a critical examination of the current application of environmental biotechnologies in the field of bioremediation of contaminated groundwater and sediments. Based on analysis of conventional technologies applied in several European Countries and in the US, scientific, technical and administrative barriers and constraints which still need to be overcome for an improved exploitation of bioremediation are discussed. From this general survey, it is evident that in situ bioremediation is a highly promising and cost-effective technology for remediation of contaminated soil, groundwater and sediments. The wide metabolic diversity of microorganisms makes it applicable to an ever-increasing number of contaminants and contamination scenarios. On the other hand, in situ bioremediation is highly knowledge-intensive and its application requires a thorough understanding of the geochemistry, hydrogeology, microbiology and ecology of contaminated soils, groundwater and sediments, under both natural and engineered conditions. Hence, its potential still remains partially unexploited, largely because of a lack of general consensus and public concerns regarding the lack of effectiveness and control, poor reliability, and possible occurrence of side effects, for example accumulation of toxic metabolites and pathogens. Basic, applied and pre-normative research are all needed to overcome these barriers and make in situ bioremediation more reliable, robust and acceptable to the public, as well as economically more competitive. Research efforts should not be restricted to a deeper understanding of relevant microbial reactions, but also include their interactions with the large array of other relevant phenomena, as a function of the truly variable site-specific conditions. There is a need for a further development and application of advanced biomolecular tools for site investigation, as well as of advanced metabolic and kinetic modelling tools. These would allow a quicker evaluation of the bioremediation potential of a site, and in turn a preliminary assessment of the technical feasibility of the chosen 


\section{bioprocess which could replace or at least reduce the need for time-consuming and expensive field tests. At the same time, field tests will probably remain unavoidable for a detailed design of full scale remedial actions and the above reported tools will in any event be useful for a better design and a more reliable operation.}

\section{Introduction}

\section{Background}

After more than two centuries since the start of industrialisation and due to the increased use of xenobiotics and hazardous materials in many production processes, Europe is now facing the problem of contamination of soil, groundwater and sediments. More recently, the environment policies adopted on waste reduction, water protection, and environmental liability are enforcing a strong array for protection of environmental resources against future risks. In particular, the European Directive on environmental liability [1] established a common liability framework across the EU, to be applied when soil and groundwater contamination creates a significant risk for human health and/or damage of environmental resources. Unfortunately, the common liability regime does not apply to historical contamination or to damage which occurred prior to its entry into force, which still represent most frequent cases of site remediation.

As for establishing a more specific framework for protection of soil, the European Commission also adopted the communication 'Towards a Thematic Strategy on Soil Protection' [2] and a Proposal for a Directive of the European Parliament and of the Council is still under discussion [3]. In this context, the number of potentially contaminated sites and the number of sites actually contaminated and needing remediation have been estimated at 3.5 and 0.5 million, respectively, has been estimated at 0.5 million. Moreover, annual costs of soil contamination have been estimated in the range $€ 2.4-17.3$ billion [3].

According to the Proposal, Member States will have to perform a preliminary survey of potentially contaminated sites, to be based on a pre-established screening list of potentially dangerous industrial activities, which will produce a priority list of sites to be further investigated to determine which sites are actually contaminated and need remediation. The costs for preliminary survey are estimated at about $€ 51$ million per year (at the European level), followed by on-site investigations (up to $€ 240$ million yearly), to finally conclude whether there is a significant risk to the human health or environment. In the perspective of such an enormous effort, new approaches to site remediation should be developed and implemented to increase the 'sustainability' of remediation, both in the environmental and economic sense. Indeed, a European survey (EURODEMO, 2006) confirmed that the Dig and Dump (D\&D) and Pump \& Treat (P\&T) remain the most common approaches to soil and groundwater remediation, respectively [4].

On the contrary, we should move forward from such waste- and energy-intensive approaches, towards more sustainable remediation approaches, to:

- recover natural functions and potential uses of environmental resources to be remediated (e.g. quantitative and qualitative preservation of groundwater resources);

- minimise extraction of water and production of wastes to be disposed of;
- favour the continued economic use of the site during remediation.

\section{Inventory of remediation technologies at contaminated sites in Europe}

A single comprehensive source of remediation activity information does not exist in Europe. The desired information has to be compiled from different sources, bearing in mind that quantitative data are not always mutually comparable. Hence, the country-wise display of projects and technologies is often unrepresentative. In addition, the available information is often incomplete, as only a portion of the existing remediation projects or technological applications are provided. Hence, the numbers presented in the text below cannot claim to be complete, representative, or comparable.

\section{Site remediation in Italy}

In Italy, there are presently 38 sites whose remediation is considered to be of national interest, based on their environmental relevance (National Programme for Site Remediation). Any remediation action at these sites has to be formally approved by the Ministry of Environment and a national financial support was made available mainly for emergency containment of contamination. Many sites from the National Programme are so called 'megasites', including seven that are larger than 10,000 hectares (ha) and many sites larger than 100 ha. These sites include all main industrial fields and accordingly a wide range of contaminants is present in soil, subsoil and groundwater thereof. Many sites are located in coastal areas, including harbours and lagoons; hence, the related pollution also often extends to shallow sediments.

Moreover, it has been estimated that about 15,000 contaminated sites of minor relevance will have to be remediated or at least monitored, at a cost of about $€ 25-30$ billion over the next 15 years.

When a groundwater is contaminated, the Italian national rule requires that emergency safety actions are taken, so as to avoid the spreading of the contaminated plume and the deterioration of nearby connected water bodies. Due to their rapid viability, emergency actions are usually achieved by passive (cut-off walls and drainage trenches) or dynamic barriers (hydraulic barriers) and their realisation brings with it the need for 'pump-and-treat' (P\&T). Moreover, the large use of P\&T systems is due to their ease of design and control, being based on adduction to a treatment plant and a final control of a localised effluent. A recent study concerning 17 National Sites in Italy, estimated an investment cost of $€ 604 \mathrm{M}$ for P\&T systems, based on either hydraulic containment or impermeable walls and drains. $41 \%$ of the investment cost was for new and ad hoc designed 'groundwater' treatment plants for which the average unit investment cost was around $€ 50,000$ / (mc/h) [5]. The estimated overall flow rate was $45 \mathrm{Mm}^{3} / \mathrm{y}$ (about 500,000 inhabitant equivalents) with an average operation cost of $€ 2.4 / \mathrm{m}^{3}$. The high operation cost was mostly due to the most 
frequent use of physical-chemical treatment and very low threshold levels to be achieved, even though reinjection of treated groundwater was seldom preferred. The time frame of P\&T systems was usually undefined.

\section{Site remediation in Austria}

The main information source is the Register of Contaminated Sites [6], a register operated by the Umweltbundesamt in Austria. As of January 2009, 248 areas appear in the Register on the basis of investigations and risk assessments. Ninety-seven of these sites have already been secured or remediated. Securing or cleanup measures are underway for 92 of the remaining 151 contaminated sites.

Dig \& Dump (D\&D) was a dominant remediation component whereas non-conventional methods have relatively few applications in comparison. One example of Permeable Reactive Barrier (PRB) was reported as very successful (e.g. [7]). In this regard, a policy support project, Contaminated Sites Management 2010 was initiated, the overall objective of which is to amend the current system according to more sustainable principles.

\section{Site remediation in Germany}

The information source was the German Referenzkatalog Altlasten/Schadens-fallsanierung (RefAS) [8]. The RefAS catalogue, comprising about 1000 remediation projects, was published in 1995 to make it possible for remediation planners to take advantage of experience coming from projects with comparable specifications. Here it can be seen that D\&D and P\&T are mostly applied, but treatment by biological, physical and thermal methods has also been used. The high application numbers suggest that treatment methods are rather well developed and reliable. Additionally, several Permeable Reactive Barriers (PRB) projects exist in Germany $[9,10]$.

\section{Site remediation in United Kingdom}

The CL:AIRE remediation survey undertaken in 2005 [11] reveals that around $41 \%$ of remediation activities undertaken have a D\&D component; on the other hand, a high amount of biological measures have been also undertaken in the UK and the numbers provided suggest that the UK has a broad experience in remediation.

\section{Site remediation in Spain}

More than one third of the Spanish national areas contain aquifers. Nearly a quarter of the water consumed can be obtained from groundwater resources. The Spanish government has been monitoring groundwater quality since 1992 and collecting basic data for the National Groundwater Research Plan. The sampling sites [12] are distributed evenly within the groundwater regions, 2726 sites in porous media, 1411 in karst area and 2439 sites in isolated control points [13]. As regards quality, groundwater presents different levels of pollutants (chlorides, sulphate, nitrate, nitrite, metals and pesticides) depending on which river basin district it is found in. In 2002, the EU identified and estimated 4910 and 18,142 contaminated sites of which 370 were in preliminary investigation, 37 under implementation of remediation activities and 59 completely remediated [14]. In 2007, the EU presented an overview of contaminants affecting soil and groundwater in Spain (expressed as \% abundance): heavy metals 39.2\%, mineral oil $22.6 \%$, others $12.3 \%$, phenols $9.3 \%$, chlorinated hydrocarbons (CHC) $7.2 \%$, polycyclic aromatic hydrocarbons (PAH) $4.5 \%$, aromatic hydrocarbons (BTEX) 3.6\% and cyanides $1.2 \%$.

\section{Other information}

In the Netherlands, 74 full-scale in situ remediation projects have been documented during the course of a European project called Case Based Reasoning [15]. This database was developed with the aim to design a tool whereby new in situ projects could be designed based on experience gained from projects already performed. In this database, more than 60 in situ bioremediation technology applications are reported, which shows a great interest in this method in the Netherlands.

Another interesting source of information is the Eurodemo demonstration project database [16]. This public database was initiated by the EC funded project Eurodemo and is geared to collecting information on innovative demonstration projects in Europe with 'demonstration' meaning 'post-pilot, full scale implementation of a technology $(\ldots)^{\prime}$. This implies that the remediation approach is not yet commercial. The data in this database is supplied by volunteer reporters who can thereby promote remediation projects in which they are involved.

\section{Conclusion}

Based on available sources of information, a variety of methods is applied throughout the countries illustrated, but with a clear predominance of conventional methods. Nevertheless, innovation appears to be an important topic for several countries, and a stronger effort would be necessary for the gained experience on innovative remediation approaches at national level to become more visible and accessible at a European level, for example through improved transnational knowledge transfer. By better connecting European experiences on site remediation, a quicker development of innovative and effective technologies could be achieved while simultaneously minimising duplication of efforts, to the benefit of all involved parties. Moreover, the competitiveness of European technologies could strengthen the European position in the global market for remediation technologies [17].

\section{Conventional versus sustainable remediation of contaminated groundwater Conventional plume management through $P \& T$}

In almost all sites, a groundwater contaminated plume is formed as a result of the contamination. To prevent potential targets (e.g. drinking water wells) from being impacted by the contamination, a plume containment and/or remediation system needs to be put in place. For several reasons, this is most commonly realised by means of a P\&T approach, whereby the extracted groundwater is usually treated in physical-chemical units based on air stripping, activated carbon adsorption, precipitation, flocculation, among others.

The P\&T approach has several drawbacks:

- it is often associated with a high request for energy and treatment costs (pumping, adsorbent materials, regeneration); moreover presently used processes for treatment of contaminated groundwater are mainly an adaptation of those originally developed for industrial wastewater treatment. As for chlorinated 
compounds, this is basically achieved through activated carbon adsorption, which has very high operating costs and requires a post-treatment step to actually 'destroy' the chlorinated compounds (e.g. during thermal regeneration of activated carbon).

- contaminants are often strongly adsorbed onto the solid phase or even present as a separate phase in the subsurface (Light or Dense Non Aqueous Phase Liquid, LNAPL or DNAPL, respectively), that is removal rate is mostly controlled by the slow dissolution kinetics and the P\&T system has to be maintained in operation for long time. Moreover, long operational times required are hardly considered during the design and cost analysis of the P\&T systems.

- with respect to the final fate of the treated water, reinjection or reuse are not the preferred alternative due to stringent regulatory issues. Most frequently, the 'treated' groundwater is discharged into surface waters or into the sewage, for which less stringent discharge limits are typically permitted. In other words, P\&T cannot preserve the groundwater as a quantitative resource, potentially available for human use.

Differently, in situ treatments make it possible to carry out the remedial action directly below the ground, targeting either the contaminant plume or the contamination source directly. These treatments offer potential advantages such as lower operating costs (due to lower request for energy), the absence of external effluents to be treated and discharged, as well as less disturbance to the original use of the soil. Moreover, in situ treatments usually allow effective degradation of contaminants rather than simple phase transfer.

On the other hand, chemical or even biological in situ treatments may cause the possible onset of secondary contamination (i.e. accumulation of intermediates as toxic or parent compounds) and may present difficulties in reaching the requested low
Threshold Values (MCLs). Furthermore, in situ treatments require a deeper understanding of local conditions and standardised protocols and methodologies for their design and monitoring are not yet fully developed. For this reason, in situ technologies suffer from a lack of 'cultural' consensus from the administrative audience and local authorisation is sometimes problematic to obtain.

\section{Outside Europe - the US experience from an EPA survey of National Priorities List}

The biennial US EPA inventory of groundwater remedial actions undertaken at contaminated sites from the National Priority List revealed that, for a long time, P\&T has been the most commonly adopted remediation approach also in the US [18,19]. For the period 1982-2005 [18], 83\% of the sites considered included a P\&T system and in around 56\%, P\&T was the only approach implemented. It is also worth noting that, in spite of the fact that the survey covered a period of over 20 years, out of the 725 P\&T projects, $521(72 \%)$ were still operational and only $73(10 \%)$ had been completed and ultimately shut down.

However, a new trend in groundwater remediation has emerged in the US since 1997, showing a substantial increase of in situ remediation applications versus a gradual, yet continued, decline of those based on P\&T (Fig. 1 [19]).

Among in situ technologies, in most recent years bioremediation has surpassed both chemical treatment and air sparging, becoming the in situ technology most applied for groundwater remediation in the period 2005-2011 (Fig. 2 [19]).

\section{Potentials and barriers for further implementation of in situ technologies}

As above reported, in situ technologies are good candidates to replace D\&D and P\&T wherever possible, because they usually:

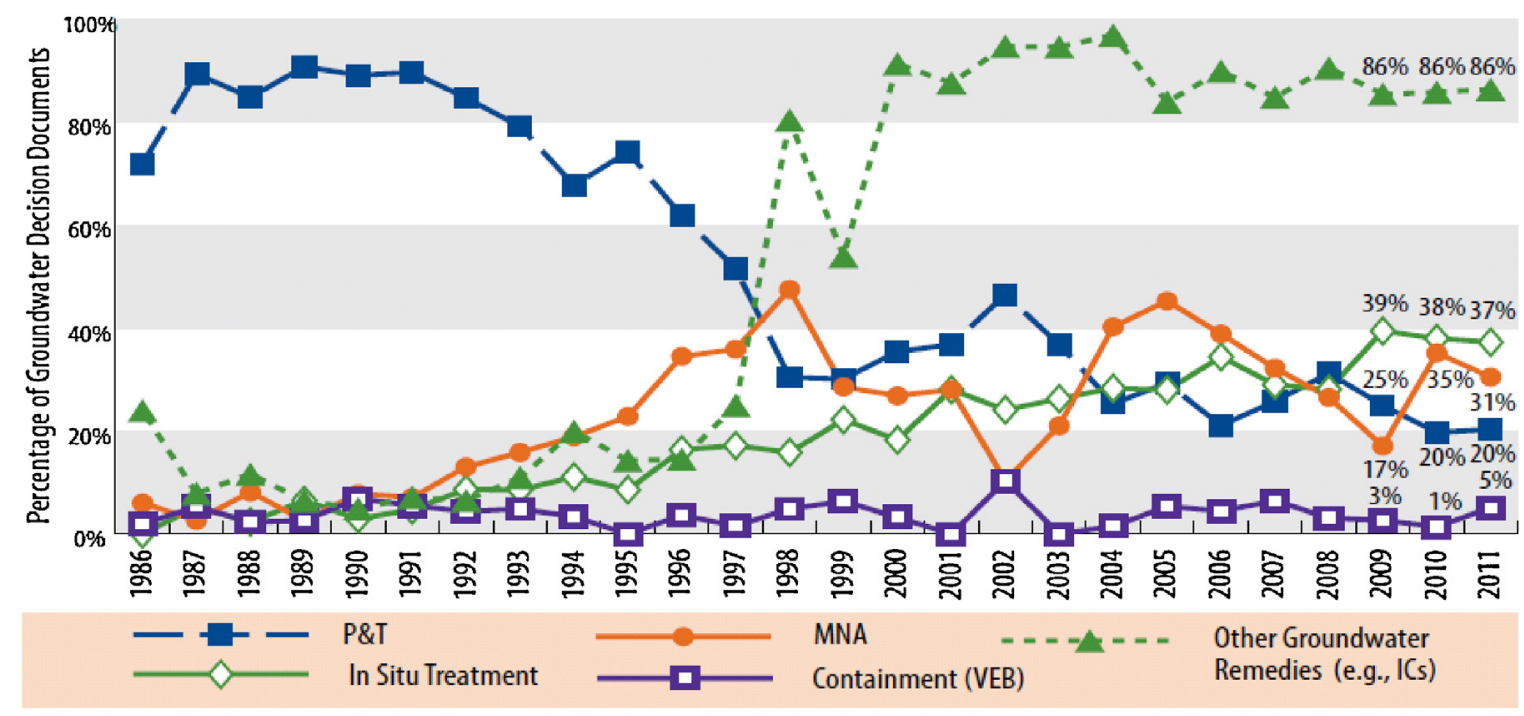

- Number of groundwater decision documents $=1,919$.

- Decision documents may be induded in more than one category.

\section{FIGURE 1}

Trends of distribution of groundwater remediation technologies applied at contaminated sites of the US National Priorities List (1985-2011) [taken from ref. [19]]. ROD: Record of decision. 


\begin{tabular}{|c|c|c|c|c|}
\hline Technologies & $\begin{array}{r}\text { Total } \\
\text { (FY05-08) } \\
\end{array}$ & $\begin{array}{r}\text { Percent } \\
\text { Groundwater } \\
\text { Decision } \\
\text { Documents } \\
\text { (FY05-08) }\end{array}$ & $\begin{array}{r}\text { Total } \\
\text { (FY09-11) }\end{array}$ & $\begin{array}{r}\text { Percent } \\
\text { Groundwater } \\
\text { Decision } \\
\text { Documents } \\
\text { (FY09-11) }\end{array}$ \\
\hline Pump and Treat & 85 & $26 \%$ & 45 & $22 \%$ \\
\hline Groundwater Pump and Treat & 82 & $25 \%$ & 44 & $21 \%$ \\
\hline Surface Water Collect and Treat & 5 & $2 \%$ & 1 & $<1 \%$ \\
\hline In Situ Treatment & 97 & $30 \%$ & 79 & $38 \%$ \\
\hline Bioremediation & 60 & $19 \%$ & 49 & $24 \%$ \\
\hline Chemical Treatment & 38 & $12 \%$ & 28 & $14 \%$ \\
\hline Air Sparging & 10 & $3 \%$ & 12 & $6 \%$ \\
\hline Permeable Reactive Barrier & 7 & $2 \%$ & 8 & $4 \%$ \\
\hline In-Well Air Stripping & 0 & $0 \%$ & 2 & $1 \%$ \\
\hline Multi-Phase Extraction & 1 & $<1 \%$ & 2 & $1 \%$ \\
\hline Phytoremediation & 3 & $1 \%$ & 0 & $0 \%$ \\
\hline Fracturing & 1 & $<1 \%$ & 0 & $0 \%$ \\
\hline MNA of Groundwater & 116 & $36 \%$ & 56 & $27 \%$ \\
\hline Groundwater Containment (VEB) & 16 & $5 \%$ & 6 & $3 \%$ \\
\hline Constructed Treatment Wetland & 1 & $<1 \%$ & 4 & $2 \%$ \\
\hline For Groundwater Treatment & 1 & $<1 \%$ & 3 & $1 \%$ \\
\hline For Surface Water Treatment & 0 & $0 \%$ & 1 & $<1 \%$ \\
\hline Other Remedies & 281 & $87 \%$ & 177 & $86 \%$ \\
\hline Institutional Controls & 274 & $85 \%$ & 173 & $84 \%$ \\
\hline Alternative Water Supply & 26 & $8 \%$ & 13 & $6 \%$ \\
\hline Engineering Control & 4 & $1 \%$ & 2 & $1 \%$ \\
\hline
\end{tabular}

\section{FIGURE 2}

Most diffused in situ treatments for groundwater remediation at contaminated sites of the US National Priorities List (1985-2011) [taken from ref. [19]].

- do not require external treatment and water discharge,

- require no or less pumping energy,

- cause less disturbance of land use,

- are based on effective degradation of contaminants, not only on phase transfer,

- can be more oriented towards the contamination source rather than the plume,

- can be effective on separate phases (e.g. chlorinated DNAPLs). On the other hand, some possible drawbacks are:

- it may be difficult to reach very low MCLs,

- 'injection' of substances into groundwater is often required, with specific limitations,

- caution about possible secondary contamination is necessary (e.g. toxic intermediates or side-products).

More generally,

- the implementation of in situ technologies is more site-specific and requires very good expertise on underlying processes (so called knowledge-intensive approach),

- design methodology is less standardised and pilot-scale field tests are required for appropriate design,

- because field tests often require specific authorisations, a preliminary agreement has to be reached among managers, technician and public authorities,
- hence, appropriate design of in situ technologies is more timeconsuming and expensive, and in addition the time needed to reach remediation objectives can be longer.

To overcome these possible drawbacks, any contaminated site should be considered and dealt with as a 'case study', where the forefront of scientific and technical knowledge should be used. To achieve this aim, the most accurate 'up-stream' knowledge is needed to:

- perform site-sensitive characterisation and accommodate it to the processes under evaluation,

- combine techniques (chemical, geophysical, microbiological, isotopic),

- look for secondary sources (e.g. DNAPL) and try to focus as closely as possible to the sources, to minimise the volumes to be treated,

- calibrate the remediation to the rate-determining step (e.g. dissolution or desorption of contaminants from separate phases) and take advantage of downstream natural attenuation processes.

As for evaluation of 'down-stream' impacts, the following issues should be considered:

- preservation of natural conditions (organic matter, soil texture, biological activity) as far as possible, 
- evaluation of all potential impacts (identification of possible toxic intermediates, side- or end-products, ecotoxicology tests) - appropriate calibration of monitoring of remediation targets and potential impacts.

Of course, such a general approach needs to be tuned to different matrixes, contaminants and technologies under evaluation. As an example, some in situ technologies, such as soil vapour extraction, air sparging, and in-well stripping, are well established and require simpler and a less case-sensitive design. However, these technologies are actually based on in situ phase transfer of contaminants and on-site treatment of gas phase, that is they suffer, to a more limited extent, for some of the drawbacks of the P\&T approach. Similarly, other emerging technologies, such as soil flushing and in situ thermal treatment, are mainly based on further acceleration of in situ phase transfer. Hence, they require good comprehension of physical-chemistry, geochemistry and hydrogeology aspects under strongly modified conditions. Finally, other techniques (such as chemical oxidation, (bio)electrochemical remediation, and bioremediation) are based on induction and/or enhancement of in situ degradation of contaminants and require full understanding of in situ degradation mechanisms, including modifications that are caused to the environmental matrixes to be remediated. In general, all techniques where chemical substances have to be added are considered cautiously because of possible negative modifications of aquifer and natural soil conditions. In this respect, thermal or chemical techniques can in principle be assumed to cause stronger modifications than biological techniques. As a golden rule, techniques that simply accelerate transport and 'natural' degradation mechanisms are to be preferred (i.e. enhanced natural attenuation). Moreover, the choice of mild technologies by which remediation is achieved over a longer time should not necessarily considered as negative, if coherently tuned to down-stream environmental protection and to present or future site use.

From this short summary, it is evident that the concept of 'sustainability' in the field of site remediation still requires to be detailed and the comparative evaluation of techniques remains mainly an empirical exercise. Under the EU FP7, several research actions have been taken in this context and include coordination and demonstration programmes on innovation in remediation technologies, as well as development of certification procedures for advancement of environmental technologies and expert systems (see below).

In this context, bioremediation, that is the destruction, detoxification, or immobilisation of harmful compounds by living microorganisms, has gained wide interest as an environmentally friendly and cost-effective alternative to physic-chemical methods. The high metabolic versatility of microorganisms makes bioremediation applicable to a large and ever-increasing number of environmental pollutants, such as pesticides, industrial chemicals and fuels. Even compounds that were once believed to be recalcitrant, such as chlorinated solvents, polychlorobiphenyls (PCBs), methyl ter-butyl ether (MTBE) and other synthetic organics, have been shown to be degradable by microorganisms. Finally, the bioremediation approach has also been extended to inorganic elements and compounds, either in anionic (such as nitrate) or cationic form (such as heavy metals).

An exhaustive examination of all possible applications of in situ bioremediation for all environmental matrices and related contaminants is outside the purpose of the present paper. In the following sections a few examples of the application of biotechnologies for in situ remediation of contaminated groundwater and sediments are presented.

\section{In situ bioremediation of contaminated groundwater}

The key feature of in situ bioremediation systems is that the aquifer is used as the biological reactor for contaminant biodegradation, under natural or enhanced conditions.

Enhanced in situ bioremediation is usually based on the manipulation of environmental conditions within the contaminated aquifer to increase the microbial activity (including the increase of contaminant availability); this can be achieved through the addition of nutrients or electron donors/acceptors and/or control of $\mathrm{pH}$, redox state, or temperature. If necessary, the kinetics and effectiveness of in situ bioremediation can be increased through the introduction of exogenous microorganisms having the necessary metabolic capabilities (bioaugmentation). In the following, examples are given for some relevant cases.

\section{Chlorinated solvents}

Chlorinated aliphatic solvents (chlorinated methanes, ethanes, ethenes) are a large family of compounds that are used in several industrial applications (chemical cleaning, dry cleaning, textile dyeing, solvent formulations, among others). Due to improper use and disposal, chlorinated aliphatic solvents are among the most common organic contaminants of groundwater throughout Europe.

Chlorinated solvents are highly toxic and some are also carcinogenic, so their presence in groundwater is considered unacceptable (or at least potentially critical) even at very low concentration levels. Moreover, many chlorinated solvents can occur as dense non-aqueous phase liquids (DNAPLs). Once released, DNAPL can migrate through the soil and reach the groundwater table. An aliquot of DNAPL (referred to as 'free' or 'mobile' DNAPL) then moves downward through the aquifer and eventually forms 'pools' on low permeability surfaces, such as clay layers. DNAPL movement is more often controlled by gravity than by hydraulic head in the groundwater. Therefore, a thorough understanding of site geology and hydrogeology is needed before likely locations and pathways of DNAPL movement can be identified. Both the residual and mobile DNAPL act as long-term slowrelease sources of groundwater contamination, that continuously dissolve into the water flow, often generating large contamination plumes. Clearly, a full appreciation of the environmental factors affecting the fate of chlorinated solvents in subsurface environments is necessary to eventually implement appropriate remedial actions.

In the aquifer, chlorinated aliphatic solvents can be transformed via several reactions, either abiotic or biotic, the latter being usually predominant.

The strong electro-negativity of chlorine atoms gives an oxidising character to polychlorinated aliphatic compounds, so that they can be reductively dechlorinated by serving as respiratory electron acceptors. Microbially mediated reductive dechlorination (RD) usually occurs through (1) hydrogenolysis and (2) dichloroelimination. In hydrogenolysis, a chlorine atom is replaced by a hydrogen atom, with a net input of two electrons. As an example, 
the RD of perchloroethylene (PCE) proceeds to ethene through a sequence of hydrogenolysis steps, involving the intermediate formation of trichloroethene (TCE), cis-dichloroethene (cisDCE) and vinyl chloride (VC). Dichloroelimination is the concomitant removal of two chlorine atoms from vicinal carbon atoms, which results in the formation of a double bond between the two carbon atoms, requiring a net input of two electrons. Chloroethanes can also undergo dehydrochlorination, that is the concomitant removal of a halogen and a hydrogen atoms from adjacent carbons, so converting an $(n)$ chlorinated alkane into the $(n-1)$ chlorinated alkene. Dehydrochlorination is an abiotic reaction which does not require the input of electrons.

The full understanding of factors controlling the relative extent of these different reaction pathways as function of field conditions is required because intermediate daughter products can have different persistence, mobility, and toxicity. As an example, the dechlorination of tetrachloroethane (TeCA) can occur via hydrogenolysis, dichloroelimination and dehydrochlorination (Fig. 3); depending on the pathway, the toxic vinyl chloride may either be formed or not [20].

As for the microbiology of the RD process, several bacteria have been isolated that can couple RD to energy conservation and growth (metabolic RD) [21,22]. However, these microorganisms have quite different characteristics, in terms of required electron donors, intrinsic kinetics, dechlorination end-points and resistance to substrate inhibition. As an example, several strains are restrictive as for the electron donor, (e.g. Dehalobacter and Dehalococcoides that can only utilise $\mathrm{H}_{2}$ ), whereas other strains (Dehalospirillum, Desulfitobacterium) are more versatile. Remarkably, only members of the genus Dehalococcoides seem to be able to drive the $\mathrm{RD}$ of chloroethenes to harmless ethene.

Presently, microbial dechlorination is the one of the most promising approaches to in situ remediation of groundwater contaminated by chlorinated solvents. A survey of 93 sites worldwide (mostly in the USA, but also in the UK, the Netherlands and Japan) has been published by the Environmental Security Technology Certification Program, ESTCP (www.estcp.org), whereby enhanced in situ anaerobic bioremediation has been applied or is ongoing (21 sites at full scale, nine sites at pilot and full scale, 59 sites at pilot scale). To stimulate the RD activity of native dechlorinating populations, several substrates were used as electron donors, including single soluble compounds (14 lactate, three butyrate, three acetate, six others), soluble or emulsified mixtures of substrates (15 molasses, 10 vegetable oils), slow-release polymers $\left(35 \mathrm{HRC}^{\circledR}\right.$, polylactate-based, commercialised by Regenesis Inc.), organic solids (three mulch, one chitin), and gas (three molecular $\mathrm{H}_{2}$ ). Of course, each type of substrate required appropriate and different delivery systems. Several protocols have been proposed to drive the evaluation processes and the preliminary design of in situ enhanced bioremediation through RD. As an example, the RABITT protocol [23] makes a preliminary site assessment by using a ranking system which includes contaminants, geochemical and hydrogeological data. Hydraulic conductivity is the most important parameter to assess whether substrate addition can be appropriately managed. A treatability study then has to be performed by using microcosms and/or field studies. In a similar approach [24], the preliminary screening system is based on 'red flags' (occurrence of negative conditions that exclude effective application of $\mathrm{RD})$. More generally, a typical flow-sheet of an evaluation procedure that should be adopted for application of RD is presented in Fig. 4.

The available knowledge of the environmental factors affecting the RD process is typically insufficient to predict the likelihood of success of an in situ bioremediation treatment. Ad hoc microcosm studies (possibly conducted under conditions that closely resemble those occurring in situ) and field tests often need to be performed. Microcosms are particularly useful to:

- verify the presence and activity of native dechlorinating microorganisms and individuate possible end-products

- identify the type and optimal amount of electron donor and/or growth factors to be added

- evaluate the influence of competing metabolisms and their effects on substrate dosage

- evaluate effects of co-contaminants and other substances in the groundwater (e.g. inhibition), including any accumulation of toxic intermediates or side-products

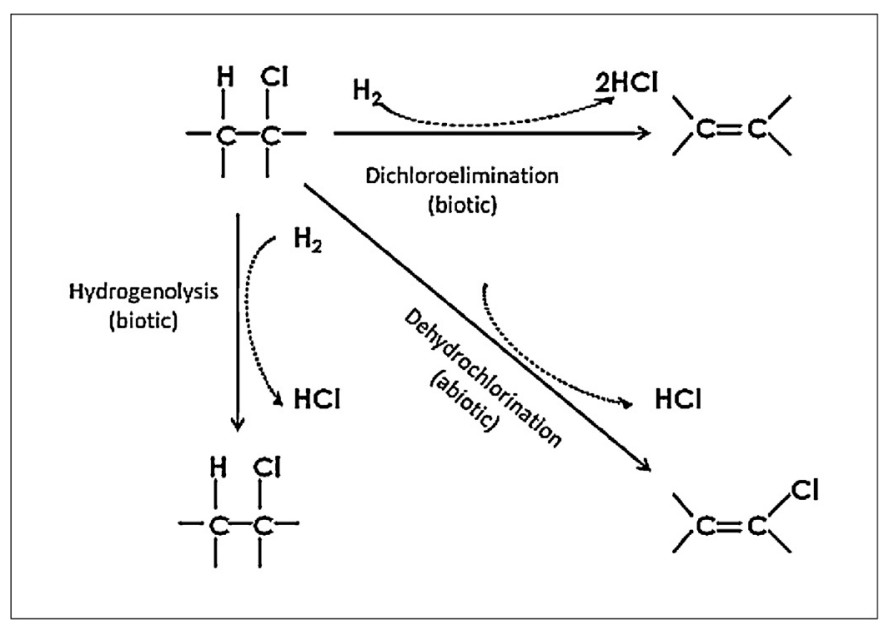

FIGURE 3

Possible dechlorination pathways relevant to the degradation of aliphatic chlorinated hydrocarbons.

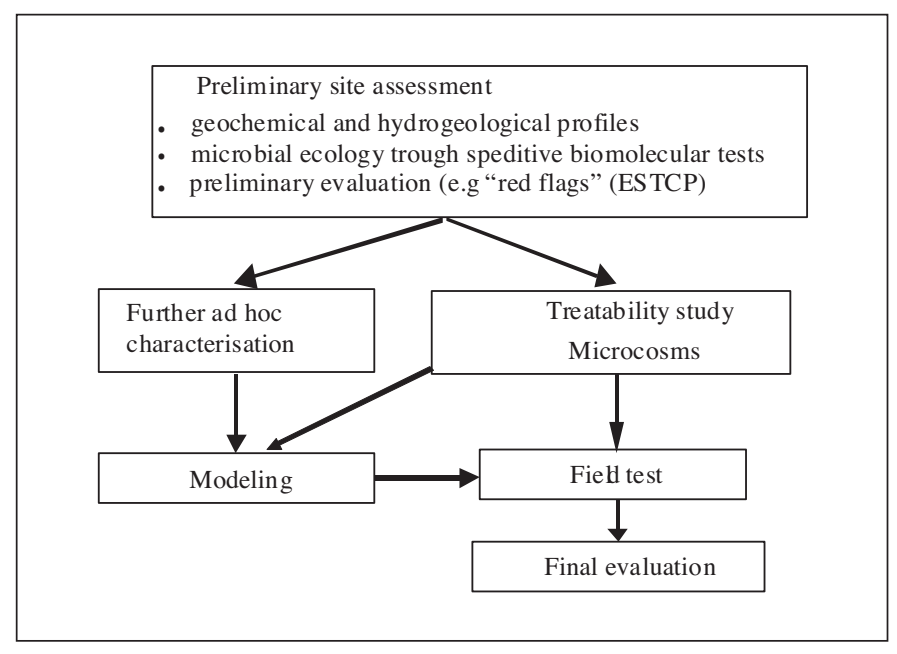

FIGURE 4

In situ RD evaluation flow-chart. 
- verify the need and effectiveness of bioaugmentation with specialised inocula.

Besides microcosm studies, small-scale field tests should be also conducted, particularly when the presence of a DNAPL is anticipated. Although more expensive and time-consuming, a pilot test is more representative because it probes a much larger volume of the aquifer; furthermore it evaluates whether microorganisms can grow over time and become more active and widely distributed within the treatment zone, even if they were initially present in only a relatively small number. Information about the costs of both field tests and microcosms studies based on the RABITT protocol at different sites have been recently published [25]. A total cost in the range of $\$ 84-111 \mathrm{~K}$ or $\$ 124-154 \mathrm{~K}$ is reported for a field test involving a $10 \mathrm{~m}$ or $60 \mathrm{~m}$ drilling, respectively. As for the microcosm studies, a total cost in the range of $\$ 77-94 \mathrm{~K}(10 \mathrm{~m}$ depth of drilling) or $\$ 94-111 \mathrm{~K}$ (60 m depth of drilling) is reported.

To be successful, field tests need a careful design, operation, and monitoring. Indeed, the design of a field test is considerably more variable than a microcosm procedure, depending on remedial target, aquifer characteristics and chosen substrate (either soluble or solid). Dealing with the addition of soluble electron donors, a small-scale field test is usually based on a pilot-scale hydraulic system, used to extract groundwater and re-inject it, after amendment in a mixing chamber. Usually, the field test is designed to: (i) create a reactive zone in the aquifer through an appropriate hydraulic control of the groundwater flow rate; (ii) control residence time in the reactive zone; (iii) obtain a good distribution of substrates in the groundwater (either by their direct injection or through groundwater recirculation); and (iv) carefully monitor inside and outside the testing area. The choice of the system arrangement should be strictly dependent on aquifer characteristics. Appropriate extraction flow rates (usually in the range of $\mathrm{L} /$ $\mathrm{min}$ ) and field scale (usually $10-20 \mathrm{~m}$ ) have to be chosen to create the appropriate hydraulically controlled reaction volume in the aquifer and to control residence time in the reaction volume (to be established based on microcosm results and usually at least 30 days). Usually, a conservative tracer test should be previously performed, along with hydrodynamic modelling to confirm good water circulation and good substrate distribution. Where the choice of an extraction-re-injection system is hindered by local regulatory constraints, internal recirculation in a single well can also be performed. In general, field tests provide a greater level of confidence in estimating the in situ extent and rate of dechlorination, and provide more information for design purposes (e.g. injection well spacing, injection pressures and frequency, substrate loading requirements). In particular situations, field tests may preclude the need for laboratory studies. However, field tests can hardly be repeated with different substrates, so the choice of the optimal one should be based on a preceding microcosm study. Moreover, surveillance and emergency procedures require considerable caution, to avoid any environmental and health risks that may derive from malfunctioning of field test (sometimes physical containment of test area is required). Hence, specific permits are required which can rate-limit the overall field test. The presence of clear and good microcosm results could make it easier to obtain authorisations for field tests and render cautions unnecessary.

Given the high specificity of the dechlorinating microorganisms, the application of molecular methods is increasingly being considered (in addition or as an alternative to microcosm studies) to qualitatively assess the 'potential' for in situ bioremediation of chlorinated solvents.

This entails the accurate enumeration of active dechlorinating bacteria or process-specific target genes under natural or engineered field conditions. To date, PCR (Polymerase Chain Reaction), qPCR (quantitative PCR) and PLFA (Phospholipids fatty acids) analysis, are practically used at field level on a somewhat regular basis. In particular, PCR-based methods (qPCR and Reverse TranscriptionqPCR) are important diagnostic tools for monitoring in situ bioremediation processes and a necessary step for the identification and gene expression estimation of functional reductive dehalogenases, the latter now considered as biomarkers for physiological activity of Dehalococcoides [26]. Certainly there have been field applications of other techniques but mostly in the context of research, not as a routinely adopted monitoring or assessment tool. Recently, FISH (Fluorescence In Situ Hybridisation) and CARD-FISH (Catalysed Reporter Deposition-FISH), which give additional information on activity and on the actual biodiversity and structure of the microbial communities [27], have been shown to be reliable and easily applicable tools for the molecular monitoring of known dechlorinators present in both laboratory bacterial enrichments and contaminated sites (Fig. 5).

While use of these tools is still quite limited, their application will grow, especially as evidence for their added value increases and as protocols and methodologies for their application become more standardised and automated. However, because of the lack of an elective molecular tool, the use of multiple molecular approaches is recommended to get multiple lines of evidence especially for the analysis of complex site samples. An overview of the main available techniques for the molecular identification of dechlorinating microbial communities, the obtainable information and their current applications, is given in Table 1.

\section{Inorganic compounds}

Water contamination with inorganic compounds (nitrate, sulphate, arsenic) is a worldwide environmental challenge. Consumption of water containing high nitrate and sulphate levels as drinking water can cause many diseases (i.e. cancer, skin irritation, an increased risk of respiratory tract infections and goitre development in children).

Groundwater under the direct influence of surface water is at particular risk of contamination by nitrates/sulphates coming from agricultural run-off and wastewater discharges. Intensive agriculture and livestock production and other nonpoint sources have also led to nitrate/sulphate pollution in aquifers around the world. In Europe, the Water Framework Directive (2000/60/EC), the Nitrates Directive (91/767/EC) and the Groundwater Directive (2006/118/EC) consider these pollutants to be the main threats to water quality, requiring urgent and intensive monitoring and strong policies. Currently, the Environmental Protection Agency (EPA) considers ion exchange, reverse osmosis and reverse electrodialysis to be effective methods for the decrease of their concentrations below their limit in drinking water. These technologies have some drawbacks, such as low selectivity towards the target pollutant, high energy or chemicals requirements and the generation of waste brine (pollutants are separated from water, not treated), which require further treatment. 


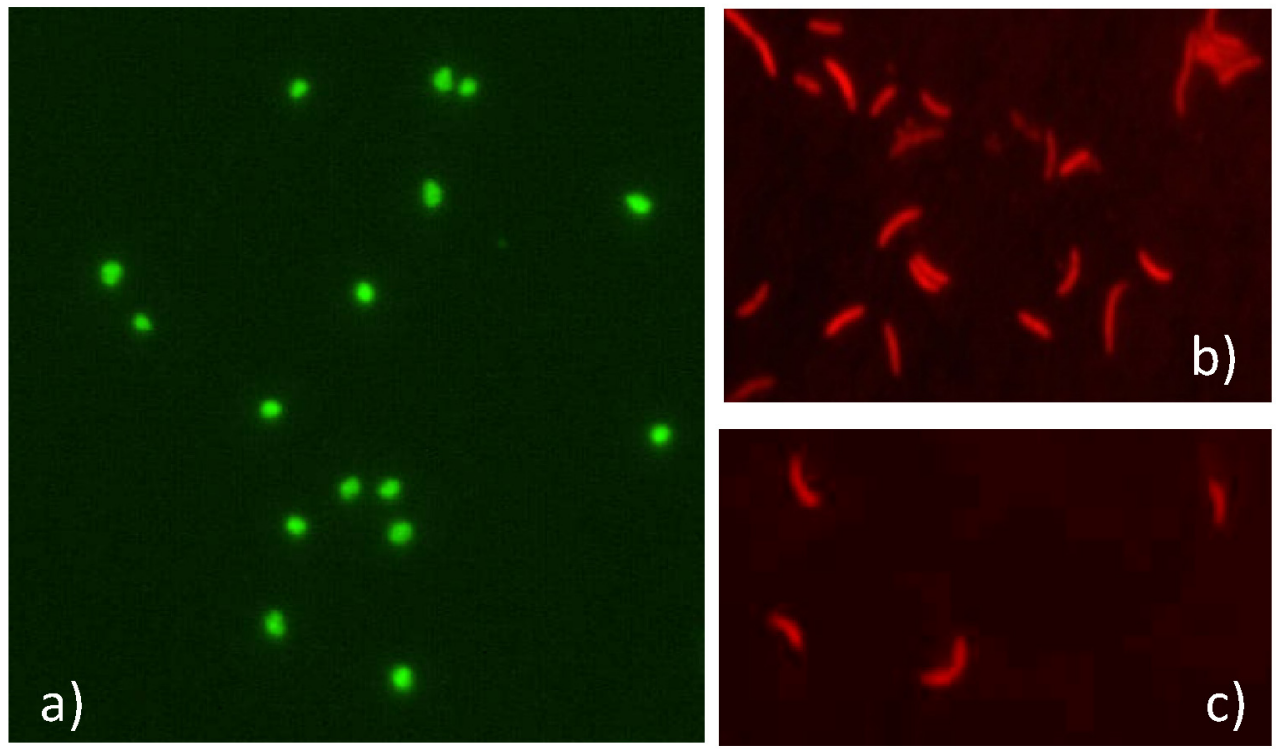

\section{FIGURE 5}

Application of in situ detection methods for the identification of dechlorinating bacteria in chlorinated solvents contaminated groundwater samples. (a) CARDFISH detection of Dehalococcoides spp. key-bacteria for reductive dechlorination of chlorinated ethenes to nontoxic ethene in contaminated aquifers. Microorganisms responsible of partial RD of chlorinated ethenes, Desulfitobacterium spp. (b) and Sulfuruspirillum spp. (c), highlighted by specific FISH oligonucleotide probes. This approach enables the direct counting of individual cells per volume or weight unit and therefore entails the accurate detection and enumeration of key microbial players involved in bioremediation processes.

Nitrates in groundwater can be treated via several reactions, either abiotic or biotic, as for chlorinated solvents (see 'Chlorinated solvents' section). Groundwater typically contains low levels of organic matter. As a result, heterotrophic biological denitrification requires the addition of an external carbon source. Autotrophic or bioelectrocatalytic denitrification is a more sustainable solution because organic carbon is not necessary to drive the reaction, and thus no carbon dioxide is released. Autotrophic denitrification can also be achieved by inorganic electron donors such as $\mathrm{H}_{2}$ through electrolysis but requiring a relatively high energy input. A broad variety of processes and reactor designs has been tested for electrocatalytic denitrification which used metals (i.e. $\mathrm{Cu}, \mathrm{Ni}, \mathrm{Zn}, \mathrm{Pd}, \mathrm{Sn}$ ) as electrode materials with energy requirements between 117 and $50 \mathrm{kWh} \mathrm{kg}^{-1} \mathrm{NO}_{3}{ }^{-}$removed [28]

The use of Bioelectrochemical Systems (BESs) permits separation of the electron donor (anode) and acceptor (cathode), which consequently reduces the impact of the treatment. BESs can reduce nitrates to $\mathrm{N}_{2}$ gas in an autotrophic biocathode, while using water or simple organic substrates such as acetate as electron donors at the anode [29]. One of the challenges of reducing nitrates to $\mathrm{N}_{2}$ gas is the stable intermediates that this reaction can generate (nitrite and $\mathrm{N}_{2} \mathrm{O}$ ). On the one hand, in terms of drinking water, nitrite is more toxic for human health than nitrate [30]; on the other, $\mathrm{N}_{2} \mathrm{O}$ is a harmful greenhouse gas. BESs have demonstrated their capability

TABLE 1

Main molecular tools for microbiological characterisation of dechlorinating microbial communities.

\begin{tabular}{|c|c|c|}
\hline Technique & Obtainable information & Current application \\
\hline Direct and nested PCR (16S rRNA gene) & Qualitative: presence/absence of $16 \mathrm{~S}$ rRNA genes of interest. & $\mathrm{F}^{\mathrm{a}}$ \\
\hline qPCR (16S rRNA gene; mRNA; functional genes) & Quantitative: presence of specific organisms of interest. & $\mathrm{F}$ \\
\hline Clone library (16S rRNA and functional genes) & $\begin{array}{l}\text { It provides data on the gene biodiversity. Very useful for FISH probe } \\
\text { design. }\end{array}$ & $\mathrm{R}^{\mathrm{b}}$ \\
\hline DGGE & $\begin{array}{l}\text { Qualitative: presence/absence of } 16 \mathrm{~S} \text { rRNA and/or functional genes } \\
\text { of interest. }\end{array}$ & $\mathrm{F}$, its application is declining \\
\hline FISH & $\begin{array}{l}\text { Quantitative; information on activity, spatial distribution and the } \\
\text { whole biodiversity of the sample. }\end{array}$ & $\mathrm{R}$ \\
\hline PFLA & $\begin{array}{l}\text { Monitoring of individual groups of organisms and for total biomass } \\
\text { determination; it can be quantitative. }\end{array}$ & $\mathrm{F}$ \\
\hline
\end{tabular}

\footnotetext{
${ }^{\mathrm{a}} \mathrm{F}$ : field application.
}

${ }^{\mathrm{b}} \mathrm{R}$ : research application. 
to reduce nitrite and $\mathrm{N}_{2} \mathrm{O}$ using a biocathode [31,32]. Consequently, a complete nitrate reduction to $\mathrm{N}_{2}$ gas can be performed using the biocathode of a BES.

Despite its relatively low direct environmental risk compared to other pollutants, in situ sulphate reduction to sulphide (toxic, corrosive and odorous) may occur under anaerobic conditions. The European Groundwater Directive (2006/115/EC) and the American Environmental Protection Agency (EPA 822-R.03-007) do take into account sulphate in the list of pollutants to consider establishing threshold values $\left(250 \mathrm{mg} \mathrm{SO}_{4}{ }^{2-} \mathrm{L}^{-1}\right)$, mostly from saline flows resulting from human activities.

Water containing sulphate is normally treated using physicochemical and biological methods. Removal of sulphate from liquid streams is restricted to anaerobic bioreactors, in which sulphatereducing bacteria (SRB) couple the oxidation of organic matter (electron donor) to the reduction of sulphate (electron acceptor), producing $\mathrm{H}_{2} \mathrm{~S}$. The inconveniences of this process mainly involve the competition of SRB with methanogenesis and the large amounts of organic matter required. However, sulphate-rich water, as in the case of nitrate contaminated groundwater, is usually deficient in electron donors. BES can provide the electrons required for sulphate reduction in a biologically activated cathode by coupling the oxidation of organic substrates in a separated anode or by direct power supply. Despite a minimum power supply being required to overcome activation energy, thermodynamic potential losses and cathode overpotentials, sulphate can be reduced via direct electron transfer when controlling the electrode at a potential which is too high $(-0.26 \mathrm{~V}$ versus SHE) for appreciable abiotic $\mathrm{H}_{2}$ production [33]. The reduction of sulphate leads mainly to sulphide production, which is entrapped in the ionic form thanks to high biocathode $\mathrm{pH}$ obtained during the process. Among all technologies used for sulphide removal, metal-sulphide precipitation could be easily applied to biocathode effluents. The high $\mathrm{pH}$ of the biocathode would increase the reactive sulphide species (i.e. $\mathrm{HS}^{-}$), enhancing metal precipitation. Different metals, such as $\mathrm{Fe}, \mathrm{Zn}, \mathrm{Cu}, \mathrm{Ni}$ and $\mathrm{Mn}$, can be used. Therefore, precipitation with metals plays a central role in controlling the dissolved sulphide concentration and the extent of associated problems. Thus, the integration of BES and sulphide recovery by precipitation may be considered a new sulphate treatment approach.

\section{Remediation of contaminated sediments}

Contaminated sediments are typically the ultimate repository for contaminants in the environment as a result of runoff and deposition. As such they pose long-term sources of contaminants for the environment, creating environmental security problems in Europe and partner countries due to the pervasive nature of sediment contamination in rivers, lakes and harbours.

The volume of sediments that have to be managed at particular sites often exceeds one million cubic meters, dwarfing many contaminated soil sites, and is also associated with equally daunting volumes of water. Processes controlling both contaminants release and their transfer (exposure and uptake) to benthic, aquatic, and land-based organisms determine the risk associated with these sediments and with the implementation of possible remedial actions. Given the relevant volume and complexity of contaminated sediment sites, few economic and effective solutions are normally available. In principle, many techniques coming from the sector of contaminated soil remediation could be also applied for the management of contaminated sediments, such as D\&D. On the other hand, much more care has to be taken to avoid the dispersion of contaminated sediments and related contaminant mobilisation, that could cause a deterioration of overlying water and unacceptable risks for biota.

Many of the problems in managing contaminated sediments have only been recognised in recent years in large contaminated sites such as the Hudson River (USA). In the USA, the US Army Corps of Engineers, the US EPA and University consortia such as the Hazardous Substance Research Center/South and Southwest have focused attention and resources on improving the understanding of contaminated sediment processes, management and remediation. In Europe, SEDNET, a loose organisation of scientists and engineers, has led the way in organising information and strategies for the management of contaminated sediments. In the field in Europe it is necessary:

a) to understand the key issues and concerns limiting sediment management;

b) to identify tools, including biological ones, for the sediment characterisation in contaminated sites;

c) to understand how the pollutant fate, in situ biodegradation and transport processes influence the final exposure to human and the environment;

d) to use sustainable techniques for the in situ remediation of sediments and overcome technical deficiencies that limit our ability to respond effectively to contaminated sediment problems with in situ sustainable approaches.

\section{Assessment}

For the assessment of contaminated sediments, there is no single 'best' method available. Each specific management question requires a tailor-made solution. Chemical analysis can be used to determine concentrations of selected hazardous chemicals. Using bioassays the bioavailable fraction of sediment contaminants and its toxic effects on organisms can be estimated together with the long term impact on sediment biota. These methods are complementary and give a unique answer that cannot be given by any of the individual methods alone. But each also has its own unique drawbacks and uncertainties [34].

\section{Management}

Contaminated sediments are mostly managed in Europe and the USA through dredging and dump site accumulation. Sediment and dredged-material management challenges and problems change with quality and quantity of material. Quality issues relate to contamination, legislation, perception, risk-assessment, source control and destinations of dredged material. Quantity issues mainly relate to erosion, sedimentation, flooding, the effects of damming and the resulting morphological changes downstream. If sediment quality impairs the ecological status, costly end-of-pipe solutions may be unavoidable for the management of contaminated sediment and dredged-material. Treatment and re-use is politically encouraged, but is currently only applied on a small scale because of the higher costs compared to disposal and the lack of product markets. However, in some cases treatment and beneficial use may be a competitive alternative to confined disposal. The latter will remain the first choice solution for the time being [34]. In recent 
years, natural attenuation has received increasing attention and it is generally accepted that microorganisms are the principal mediators of the natural attenuation of many pollutants. However, the complexity of sediments requires an interdisciplinary approach to understand microbial processes and their potential. This is even more so under in situ conditions, where the activity of pollutant degrading microorganisms is generally slow, partial and constrained spatially and/or temporally. Recent developments in molecular biology and genomics are offering tools to explore microbial processes at a level that encompasses the genetic characteristics of the local microbial players as well as their organisation into complex communities and their interactions both with each other and with the pollutants. It is now possible to study microbes directly in their environments at the population level and to link biology to geochemistry. Integrative knowledge from culture independent studies based on functional characters and assessment of the diversity and expression of catabolic genes in response to pollution, will allow a rational intervention in environmental processes. The potential of the integrated chemical, physical and biological monitoring and characterisation of polluted sediments subjected to natural decontamination has been recently demonstrated in several case studies such as (a) polychlorinated biphenyl (PCB)-contaminated marine sediments of the Porto Marghera area of Venice Lagoon (Italy) [35], (b) sediments contaminated by chlorinated aliphatic hydrocarbons (CAHs) collected from different positions of the eutrophic river Zenne (Vilvoorde, Belgium) [36], and (c) other environmental contaminated systems subjected to ex situ and in situ active bioremediation, where these processes are described on the basis of the experience accumulated in pilot and real-life systems [37].

\section{Barriers and research 'hot spots'}

\section{$R \& D$ needs in the area of in situ biological remediation of} contaminated sites

Bioremediation has a great potential to increase the sustainability of remediation of contaminated groundwater, both from the environmental and economic points of view. However, its potential is partially unexploited because bioremediation still suffers from a lack of general consensus; accordingly, regulatory permits may be more difficult to obtain than for conventional techniques, such as P\&T. With reference to in situ bioremediation, public concerns mostly relate to the possible lack of effectiveness and control, complex design and long term operation, as well as the possible occurrence of secondary effects, for example toxic metabolites and pathogens. Both basic and applied research is needed to overcome these barriers and to make bioremediation more reliable, robust and acceptable to the public as well as economically more competitive.

Many of these issues are being considered in several current FP7 projects dealing with innovative technologies for the in situ bioremediation of contaminated areas. Among them there are AQUAREHAB [38], MINOTAURUS [39,40], ULIXES [41,42], and KillSpill [43].

Research efforts should be directed at any process steps, that is 'upstream' site characterisation, bioprocess design, operation and control, and 'downstream' evaluation of effects. As for the 'upstream' step, full exploitation of bioremediation potential requires development of suitable tools allowing for a more accurate and quicker characterisation of the contaminated sites as well as a more specific evaluation of relevant bioprocesses. Firstly, this requires further development of modern biomolecular tools for the analysis of natural or modified biocenosis and their combination with other techniques, such as chemical, geophysical and isotopic analyses. This research topic should also include full exploitation of the largely unexplored biodiversity at contaminated sites as well as a strong effort to combine species-specific genetic tools (to describe which microorganisms are present) with metabolism specific ones (to describe which bioreactions are going on), so as to better describe bioremediation potential as a function of groundwater conditions. An increased use of biomolecular tools will also help to obtain a more accurate estimate of the concentration and activity of relevant microbial groups, as a function of natural or engineered conditions, to obtain a more general and robust modelling of relevant microbial processes.

As for relevant bioprocesses, research should focus on how to individuate secondary contamination sources (e.g. DNAPL) and to better understand their interactions with microbial processes. On the one hand this includes the effects of microbial processes on contaminant dissolution and mobility and, on the other, on tolerance and competition among microbial processes under high contaminant concentration. The latter point is particularly important to fit better the kinetics of microbial processes to other physicalchemical processes, that is dissolution or desorption from separate phases, in the general frame of underground hydraulics, any of them possibly being the rate determining step of the overall attenuation process.

Moreover, innovative technologies are still under study and show high potential, especially where they minimise the need for substrate or cosubstrate supply and/or make it more specific and reliable. As an example, bioelectrochemical processes do not require addition of electron acceptors or donors that are substituted from the appropriate electrochemical potential; the latter can be tuned at the desired value in well defined geometry and it appears in principle a more flexible and robust way to drive and control relevant microbial reactions [44]. In this respect, Table 2 [45] reports a range of oxidised contaminants have been recently investigated using bioelectrochemical reduction in groundwater remediation.

\section{TABLE 2}

Oxidised environmental contaminants which have been investigated for bioelectrochemical remediation.Source: modified after [45].

\begin{tabular}{lll}
\hline $\begin{array}{l}\text { Oxidised contaminant/ } \\
\text { reduced end product }\end{array}$ & $\begin{array}{l}\text { Microorganism/ } \\
\text { Mixed culture }\end{array}$ & $\begin{array}{l}\text { Biocathode } \\
\text { working potential, } \\
\text { mV (versus SHE) }\end{array}$ \\
\hline $\mathrm{NO}_{3}{ }^{-} / \mathrm{NO}_{2}{ }^{-}$ & Geobacter metallireducens & -300 \\
\hline $\mathrm{NO}_{3} / \mathrm{N}_{2}$ & Anaerobic sludge & 0 \\
\hline $\mathrm{TCE} /$ ethene & Dechlorinating culture & $-450:-750$ \\
\hline $\mathrm{TCE} /$ ethene & Dechlorinating culture & -550 \\
\hline $\mathrm{PCE} / \mathrm{cis}^{-\mathrm{DCE}}$ & Geobacter lovleyi & -300 \\
\hline $\mathrm{ClO}{ }_{4}^{-} / \mathrm{Cl}$ & Dechloromonas agitate & -250 \\
\hline $\mathrm{ClO}_{4}^{-} / \mathrm{Cl}^{-}$ & Azospira suillum & -250 \\
\hline $\mathrm{U}^{6+} / \mathrm{U}^{3+}$ & Geobacter sulfurreducens. & -300 \\
\hline $\mathrm{Cr}^{6+} / \mathrm{Cr}^{3+}$ & Anaerobic sludge & n.a. \\
\hline
\end{tabular}


The combination of biological reactions with conductive or semiconductive nanoparticles should be also studied to enhance microbial activity in a highly specific way [46]. Multipurpose reactive barriers also appear an interesting approach for long term and slow-rate release of the substrates needed, thereby supporting microbial activity in the aquifer downflow the barrier. As an example, by combining zero valent iron with biodegradable polymers, a slow release of soluble organic acids from polymer fermentation showed a positive effect on the removal rate of target contaminants by the iron and also extended the long term life of the system [47].

As for evaluation of 'downstream' impacts, it is necessary for further ecotoxicology tests to be developed and specifically calibrated to possible toxic intermediates, side- or end-products. This will be particularly useful at a pre-normative level, to establish a specific regulation helping to plan, conduct and control field tests for checking innovative technologies.

Field tests require permission, which implies that public authorities and end users are regularly involved, especially when planning research and testing of new bioprocesses. In this respect, many scientists underline that it is difficult to move from laboratory scale basic research of new processes and tools to their market exploitation, at least in the usual time frame of European Research Projects (3-4 years), especially when field tests are necessary and require specific permission to be obtained. In this respect, an innovative two step application/evaluation procedure could be explored, where the 2 nd step, including field test, is described in greater detail once a more basic research has been performed.

Full exploitation of in situ bioremediation, would also require that groundwater remediation is put into the more general perspective of groundwater protection. Indeed, it is necessary to strengthen the importance of quantitative recovery of groundwater resources and thereby the added value of in situ techniques with respect to P\&T (unless groundwater is reinjected). Furthermore, milder techniques are to be preferred (e.g. bioremediation), which enhance natural attenuation by accelerating transport and natural degradation and that in principle cause no, or fewer, modifications to the site than more aggressive techniques. This approach however requires that slow remediation approaches should not necessarily be considered as negative, if coherently tuned to the quality standards to be achieved for protection of downgradient water bodies as well as to preserve future uses of the contaminated site. In this respect, the possibility of ancillary measures for environmental and health protection (e.g. restricted admission, alternative supply of water) should be enforced to decrease the need for P\&T emergency containment while at the same time planning stronger actions on primary or secondary contaminant sources. Correspondingly, the timeframe for sustainable remediation of the source downgradient plume should be extended to take maximum advantage of ongoing natural or enhanced attenuation.

The introduction of LCA assessment in comparing different approaches (thus also including energy, chemicals, secondary effects, among others) could likely demonstrate how bioremediation is more sustainable than other techniques, especially if this general perspective is adopted.
$R \& D$ needs in the area of biological treatment of contaminated sediments

A variety of microbial processes are normally taking place in aerobic or subsurface anaerobic sediments, where bacteria and eukaryotic organisms contribute to geochemical cycles strictly cooperating through complex and often not fully elucidated mechanisms [48]. These complex communities might biotransform several chlorinated pollutants, such PCBs, PCDDs, PCDFs, among others, and some hydrocarbons, or precipitate/immobilise some toxic heavy metals [49]. If efficiently active in situ, they might mediate a significant and cost effective decontamination/ detoxification of polluted sediments $[49,50]$, thus remarkably reducing the volume of contaminated sediment to be dredged or managed through suitable in situ physical-chemical treatments.

However, little is often known about the actual relevance of microbially mediated degradation/detoxification processes in situ in marine contaminated habitats [51]. The few data coming from in situ monitoring studies generally indicate that microbiologically mediated biodegradation processes are slow, partial and very often constrained spatially and/or temporally. Further, almost nothing is currently known about possible strategies for their stimulation in situ. Such a lack of information has dramatically reduced, and is still adversely affecting, the opportunities and perspectives of biological approaches in the sustainable remediation of contaminated sediments [52].

In this context, future research should be addressed to predict better the actual potential of biological processes in the in situ restoration of contaminated sediments. This should be approached at different levels. First, through dedicated microcosm studies focused on real contaminated sediments suspended in their own site water under laboratory conditions that closely mimic those occurring in situ or in the full scale ex situ treatments, to determine the actual microbial biodegradation of aged pollutants under actual site conditions. Such investigations should rely on an integrated chemical, molecular and ecotoxicological analytical methodology, able to provide holistic information and to predict under in situ conditions (a) the fate of the pollutants, the main biodegradation products expected and their impacts on the final sediment toxicity and (b) the microbial processes (e.g. nitrate, sulphate-, Fe(III), Mn (IV)-consumption, $\mathrm{CH}_{4}$ production, among others) and the dynamics of the indigenous microbial community associated to the pollutant removal. A second level of investigation should be dedicated to the development and application of monitoring tools for the microbiological and geochemical characterisation of the underground environment. Molecular biology monitoring tools able to rapidly provide evidence of the occurrence, abundance and activity of microbial community members with the desired biodegradation/biotransformation capabilities in the contaminated site should be further implemented. In this respect, more research is needed to elucidate microbial metabolism of pollutants in sediments under different redox conditions and to identify the key catabolic genes involved, as their detection and monitoring might allow to better evaluate the intrinsic biodegradation potential of sediment indigenous communities. Future research should also address the development of new analytical and computational tools for probing complex determinants (spatial and chemical heterogeneity, coupled redox kinetics, redox-induced mineral and organic transformations, among 
others) of the various biogeochemical redox processes taking place in the subsurface, which have a decisive impact on the migration and degradation of both inorganic and organic contaminants [53]. The combination of these tools might allow the implementation of more reliable and site specific predictive models for the potential fate of pollutants in the underground environment.

Further research should also be addressed to identify effective strategies for the tailored in situ stimulation of the biodegradation processes that have shown a promising potential to occur at the site. In this respect, microcosm studies performed with nutrients and inocula might be useful for the preliminary design of a sitespecific biostimulation/biaugmentation strategy. Here a new knowledge in terms of commercially available nutrients, electron donors/acceptors and mobilising agents able to enhance pollutant bioavailability is required along with the development of suitable inocula [52]. Investigation of the possibility to apply redox manipulating compounds to drive spatially and temporally different microbial metabolisms involved in pollutants biodegradation/ biotransformation is needed. For instance, the injection of redox manipulating compounds in the hyporheic zone might enhance the dehalogenation of groundwater chlorinated aliphatic hydrocarbons (PCE, TCE, among others) flowing into the surface water and the precipitation of heavy metals such as $\mathrm{Cd}$ and $\mathrm{Zn}$ as metal sulphides [53]. Research addressed to the development of strategies and technological solutions for the in situ delivery of biostimulants and redox manipulating compounds to the contaminated sediment/water system should also be performed [52]. Finally, the possibility of developing tools and strategies to improve the interactions between indigenous microorganisms and benthic organisms deserves further attention, since the latter can mediate pollutant bioavailability enhancement, a partial pollutant biodegradation and favour the establishment of geochemical conditions that might sustain pollutant-degrading microorganisms, while the former might support benthic organisms by removing toxic pollutants and complementing their metabolism of sediment substrates [52].

\section{Concluding remarks}

In situ bioremediation is a highly promising and cost-effective technology for the sustainable remediation of contaminated sites. It can also be promising in the sustainable management of contaminated sediments. The wide metabolic diversity of microorganisms makes it applicable to an ever-increasing number of contaminants and contamination scenarios. On the other hand, the application of in situ bioremediation at a specific site is 'knowledge-intensive' and requires a deep understanding of the microbiology, biochemistry and ecology of biological systems as well as of the geochemistry and hydrogeology of contaminated soils and aquifers, and sediments, under both natural and engineered conditions. Hence, its potential is partially unexploited because bioremediation still suffers of a lack of general consensus and both basic, applied and pre-normative research is needed to make in situ bioremediation more reliable, robust and acceptable to the public awareness as well as more competitive from the economic point of view.

From the short summary of research topics, it is evident that multi-disciplinarity is really a key point because advanced research on microbes and microbial processes acting on xenobiotics and micropollutants has to be combined with many other scientific and technical fields.

Bacterial diversity is still largely unexplored, especially under 'extreme' conditions to which severe contamination from xenobiotics and emerging pollutants certainly belongs. Moreover, several innovative technologies are emerging from recent studies on how microbial activities can be linked with electrochemistry and nanoparticles. Finally, research efforts should not be restricted to a deeper understanding of relevant microbial reactions, but also of their interactions with the large array of other relevant phenomena, as a function of really variable site-specific conditions. This need calls for further development of advanced biomolecular tools in combination with advanced metabolic and kinetic modelling.

Indeed, it is certainly necessary that biomolecular tools for design and monitoring of open field bioprocesses are further developed towards improved ability to give a quantitative description of relevant phenomena at the investigated site. In other words, the 'biological section' of a predictive model should be as reliable and site-specific as its hydrogeological and hydrochemical counterpart. This would allow quicker assessment of available metabolic activities, at least for a preliminary evaluation of the technical feasibility of the chosen bioprocess, thus also being useful to substitute or at least minimise the need for time-consuming and highly expensive field tests.

At the same time, field tests will probably remain unavoidable for detailed design of full scale remediation and in this respect the above reported tools will be useful for better test design and more reliable operation, also including further implementation and intercalibration of ecotoxicological tests.

\section{Acknowledgements}

Colleagues of the Experts Group of the Environmental Biotechnology section of the European Federation of Biotechnology are kindly acknowledged for their comments on the manuscript.

MM, VT, SR, FA and RV acknowledge the European Commission within the Seventh Framework Programme under Grant Agreement No. 265946 (Minotaurus Project, www.minotaurus-project.eu). SP acknowledges the financial support of the Spanish Government (CTQ2011-23632, CONSOLIDERCSD2007-00055).

\section{References}

[1] Directive of the European Parliament and of the Council on environmental liability with regard to the prevention and remedying of environmental damage 2004/35/CE.

[2] Communication from the Commission to the Council, the European Parliament, the European Economic and Social Committee and the Committee of the Regions. Towards a Thematic Strategy for Soil Protection. EC, 2002.

[3] Proposal for a Directive of the European Parliament and of the Council establishing a framework for the protection of soil and amending Directive 2004/35/EC

[4] http://www.eurodemo.info.

[5] Majone M, Rolle E, Petrangeli Papini M, Beretta GP, Cicconi V, Maffucci M. Messa in sicurezza e bonifica di falde contaminate: un'analisi delle tecnologie impiegate a partire dall'applicazione del d.m. 471/99. La chimica e l'industria 2009:1:104-9 (in Italian).

[6] http://www.umweltbundesamt.at/umweltschutz/altlasten/altlasteninfo/.

[7] http://www.rtdf.org/public/permbarr/prbsumms/profile.cfm?mid=88.

[8] http://www.xfaweb.baden-wuerttemberg.de/alfaweb/index.html. 
[9] http://www.rubin-online.de.

[10] http://safira.ufz.de.

[11] Henstock J. CL:AIRE contractor-consultant remediation status survey 2005. In Remediation Solution 4. 2005;23.

[12] http://sig.magrama.es/recursossub/.

[13] Koreimann C, Grath J, Winkler G, Nagy W, Vogel WR. Groundwater Monitoring in Europe. European Environment Agency Topic Report 14; 1996.

[14] EEA. Environmental signals 2002 benchmarking the millennium. Copenhagen European Environmental Agency; 2002.

[15] Leijnse A, Kukuric N, Wipfler L, de Kreuk JF, Kamermans CM, Pijls C, Keijzer T. Case based reasoning: hidden soil knowledge unveiled. Learning from finished in-situ remediation projects. Final Report. Gouda, CUR/SKB; 2004.

[16] www.eugris.info/eurodemo192192/eurodemoMainProjectlist.asp.

[17] Communication from the Commission to the Council and the European Parliament. Stimulating Technologies for Sustainable Development: An Environmental Technologies Action Plan for the European Union EC 2004.

[18] EPA. Treatment technologies for site cleanup: annual status report (ASR), 12th ed., EPA; 2007 (EPA 542-R-07-012)www.clu-in.org/asr.

[19] EPA. EPA superfund remedy report, 14th ed., EPA; 2013 (EPA-542-R-13-016) www.clu-in.org/asr.

[20] Aulenta F, Potalivo M, Majone M, Papini MP, Tandoi V. Anaerobic bioremediation of groundwater containing a mixture of 1,1,2,2-tetrachloroethan and chloroethenes. Biodegradation 2006;17(3):193-206.

[21] El Fantroussi S, Naveau H, Agathos SN. Anaerobic dechlorinating bacteria. Biotechnol Progr 1998;14:167-88.

[22] Maphosa F, de Vos WM, Smidt H. Exploiting the ecogenomics toolbox for environmental diagnostics of organohalide-respiring bacteria. Trends Biotechnol 2010;28:308-16.

[23] Morse JJ, Alleman BC, Gossett JM, Zinder SH, Fennell DE, Sewell GW, Vogel CM. A treatability test for evaluating the potential applicability of the reductive anaerobic biological in situ treatment technology (RABITT) to remediate chloroethenes. ESTCP; 1998.

[24] www.estcp.org.

[25] Alleman BC, Morse JJ, Gossett JM. Cost and performance report for reductive anaerobic biological in situ treatment technology (RABITT) treatability testing. Battelle Memorial Institute; 2002.

[26] Rowe AR, Heavner GL, Mansfeldt CB, Werner JJ, Richardson RE. Relating chloroethene respiration rates in Dehalococcoides to protein and mRNA biomarkers. Environ Sci Technol 2012;46:9388-97.

[27] Matturro B, Aulenta F, Majone M, Papini MP, Tandoi V, Rossetti S. Field distribution and activity of chlorinated solvents degrading bacteria by combining CARD-FISH and real time PCR. New Biotechnol 2012;30:23-32.

[28] Duca M, Koper TM. Powering denitrification: the perspectives of electrocatalytic nitrate reduction. Energy Environ Sci 2012;5:9726-42.

[29] Pous N, Puig S, Coma M, Balaguer MD, Colprim J. Bioremediation of nitratepolluted groundwater in a microbial fuel cell. J Chem Technol Biotechnol 2013;88(9):1690-6.

[30] World health statistics; 2011.

[31] Puig S, Coma M, Desloover J, Boon N, Colprim J, Balaguer MD. Autotrophic denitrification in microbial fuel cells treating low ionic strength waters. Environ Sci Technol 2012;46(4):2309-15.

[32] Desloover J, Puig S, Virdis B, Clauwaert P, Boeckx P, Verstraete W, Boon N. Biocathodic nitrous oxide removal in bioelectrochemical systems. Environ Sci Technol 2011;45(24):10557-66.

[33] Coma M, Puig S, Pous N, Balaguer MD, Colprim J. Biocatalysed sulphate removal in a BES cathode. Bioresource Technol 2013;130:218-23.

[34] Salomons W, Brils J. Contaminated sediments in European River Basins. In: SedNet booklet. 2004;1-78.
[35] Fava F, Gentilucci S, Zanaroli G. Anaerobic biodegradation of weathered polychlorinated biphenyls (PCBs) in contaminated sediments of Porto Marghera (Venice Lagoon, Italy). Chemosphere 2003;53:101-9.

[36] Kuhn TK, Hamonts K, Dijk JA, Kalka H, Stichler W, Springael D, Dejonghe W, Meckenstock RU. Assessment of the intrinsic bioremediation capacity of an eutrophic river sediment polluted by discharging chlorinated aliphatic hydrocarbons: a compound-specific isotope approach. Environ Sci Technol 2009;43(14): 5263-9.

[37] El Fantroussi S, Agathos SN, Pieper DH, Witzig R, Camara B, Gabriel-Jurgens L, Junca H, Zanaroli G, Fava F, Perez-JimenezJR, Young LY, Hamonts KY, Lookman R, Maesen M, Diels L, Dejonghe W, DijK J, Springael D. Biological assessment and remediation of contaminated sediments. In: Reible D, Lanczos T, editors. Assessment and remediation of contaminated sediments. Springer; 2006. p. 179-238.

[38] http://aquarehab.vito.be/home/Pages/home.aspx.

[39] www.minotaurus-project.eu/.

[40] Hochstrat R, Corvini PFX, Wintgens T. MINOTAURUS: microorganism and enzyme immobilization: novel techniques and approaches for upgraded remediation of underground-, wastewater and soil. Rev Environ Sci Biotechnology 2012. http://dx.doi.org/10.1007/s11157-012-9293-8

[41] http://www.ulixes.unimi.it/.

[42] Daffonchio D, Mapelli F, Cherif A, Malkawi HI, Yakimov MM, Abdel-Fattah YR, Blaghen M, Golyshin PN, Ferrer M, Kalogerakis N, Boon N, Magagnini M, Fava F. ULIXES, unravelling and exploiting Mediterranean Sea microbial diversity and ecology for xenobiotics' and pollutants' clean up. Rev Environ Sci Technol 2012;11:207-11.

[43] http://www.killspill.eu/.

[44] Aulenta F, Tocca L, Verdini R, Reale P, Majone M. Dechlorination of trichloroethene in a continuous-flow bioelectrochemical reactor: effect of cathode potential on rate, selectivity, and electron transfer mechanisms. Environ Sci Technol 2011;45:8444-51.

[45] Rosenbaum M, Aulenta F, Villano M, Angenent LT. Cathodes as electron donors for microbial metabolism: which extracellular electron transfer mechanisms are involved? Bioresource Technol 2011;102(1):324-33.

[46] Aulenta F, Rossetti S, Amalfitano S, Majone M, Tandoi V. Conductive magnetite nanoparticles accelerate the microbial reductive dechlorination of trichloroethene by promoting interspecies electron transfer processes. ChemSusChem 2013. http://dx.doi.org/10.1002/cssc.201200748.

[47] Baric M, Majone M, Beccari M, Petrangeli Papini M. Coupling of polyhydroxybutyrate (PHB) and zero valent iron (ZVI) for enhanced treatment of chlorinated ethanes in permeable reactive barriers (PRBs). Chem Eng J 2012;195:22-30.

[48] Kafkewitz D, Togna MT. Microbes in the muck: a look into the anaerobic world. In: Lewandowski GA, DeFilippi LJ, editors. Biological treatment of hazardous wastes. USA: John Wiley \& Sons, Inc.; 1998.

[49] Lloyd JR, Lovley DR. Microbial detoxification of metals and radionuclides. Curr Opin Biotechnol 2001;12:248-53.

[50] Haggblom MM, Ahn YB, Fennell DE, Kerkhof LJ, Rhee SK. Anaerobic dehalogenation of organohalide contaminants in the marine environment. Adv Appl Microbiol 2003;53:61-84.

[51] Bedard DL, Quensen III JF. Microbial reductive dechlorination of polychlorinated biphenyls, In Microbial transformation and degradation of toxic organic chemicals. In: Young LY, Cerniglia CE, editors. Microbial transformation and degradation of toxic organic chemicals. John Wiley \& Sons Inc; 1995 p. 127-216.

[52] Fava F, Agathos SN. Uncertainty and research needs in the area of the biological restoration of contaminated sediments. Assessment and Remediation of Contaminated Sediments, 73. 2006;p. 239-46.

[53] Borch T, Campbell K, Kretzschmar R, Voegelin A, Ginder-Vogel M, Totsche KU, Barth JAC. How electron flow controls contaminant dynamics. Enviro Sci Technol 2010;44:3-6. 